\title{
LUPUS SCIENCE\& MEDICINE \\ sIL7R concentrations in the serum reflect disease activity in the lupus kidney
}

\author{
B R Lauwerys, ${ }^{1,2}$ S Nieuwland Husson, ${ }^{1,2}$ A L Maudoux, ${ }^{1}$ V Badot, ${ }^{3}$ \\ F A Houssiau ${ }^{1,2}$
}

To cite: Lauwerys BR, Husson SN, Maudoux AL, et al. sIL7R concentrations in the serum reflect disease activity in the lupus kidney. Lupus Science \& Medicine 2014;1:e000036. doi:10.1136/ lupus-2014-000036

- Additional material is available. To view please visit the journal online (http://dx. doi.org/10.1136/lupus-2014000036).

Received 16 May 2014 Accepted 24 June 2014

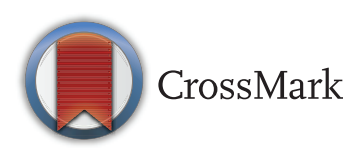

${ }^{1}$ Pôle de pathologies rhumatismales, Institut de Recherche Expérimentale et Clinique, Université catholique de Louvain, Brussels, Belgium

${ }^{2}$ Service de Rhumatologie, Cliniques Universitaires SaintLuc, Brussels, Belgium ${ }^{3}$ Service de Rhumatologie, Hôpital Erasme, Brussels, Belgium

Correspondence to Professor B R Lauwerys; Bernard.Lauwerys@ uclouvain.be

\section{ABSTRACT}

Objectives: Evaluation of disease activity in systemic lupus erythematosus (SLE) nephritis is a challenge, and repeated renal biopsies are usually needed in order to confirm a suspicion of flare. In a previous crosssectional study, we reported that serum soluble form of the interleukin-7 receptor (sIL7R) levels is strongly associated with nephritis in SLE patients. In the present study, we wanted to confirm the association between changes in serum sIL7R concentrations and renal disease activity in a large longitudinal cohort of SLE nephritis patients.

Methods: Sera were harvested longitudinally in 105 SLE nephritis patients. Serum sIL7R cut-off value for the detection of SLE nephritis activity was determined as the mean sIL7R concentration in non-nephritis SLE patients +2 SDs using data collected in our previous study. Patients with glomerular filtration rate (GFR) $<60 \mathrm{~mL} / \mathrm{min} / 1.73 \mathrm{~m}^{2}(\mathrm{n}=17)$ were excluded from the study due to persistently elevated serum sIL7R values. Results: Serum sIL7R concentrations above the renal cut-off value were observed in 25 (out of 88) patients with a normal GFR. These patients had significantly higher serum double-stranded DNA (dsDNA) Ab and urinary protein to creatinine (UPC) ratio. Strikingly, 12 of them developed a renal British Isles Lupus Assessment Group index (BILAG) A within the next 3 months, while this was only the case in four out of the 63 other patients $(p<0.0001)$. The test had $75.0 \%$ sensitivity and $81.9 \%$ specificity for the detection of a renal BILAG A. Combination of serum sIL7R with any of the classical tests (anti-dsDNA Ab titres, UPC ratio, serum C3) resulted in an increased specificity for the detection of a renal flare. Administration of immunosuppressive therapy resulted in a significant decrease in serum sIL7R concentrations.

Conclusions: Serum sIL7R is a sensitive and specific marker of renal disease activity in SLE. Elevated serum sIL7R values in SLE patients are associated with or predict the occurrence of an SLE nephritis flare.

\section{INTRODUCTION}

Glomerulonephritis is a severe complication of systemic lupus erythematosus (SLE) which occurs in $30 \%-50 \%$ of patients. Most renal manifestations of SLE are caused by the deposition of double-stranded DNA

\section{KEY MESSAGES}

- Serum SIL7R is a sensitive and specific marker of renal disease activity in SLE.

- Combination of SIL7R with any of the classical tests (anti-dsDNA titers, UPC ratio, serum C3) results in an increased specificity for the detection of a renal flare.

- Elevated serum sIL7R values decrease upon administration of immunosuppressive therapy.

(dsDNA) antibodies in the glomeruli (either trapped as DNA-anti-dsDNA immune complexes or bound to repetitive DNA-like structures in the glomerular basement membrane), where they activate complement and initiate an inflammatory response. ${ }^{1}$ The diagnosis of SLE nephritis is to be considered in patients with an abnormal urinanalysis (proteinuria, but also haematuria, pyuria or urinary casts), increased dsDNA antibody titres and, in the most severe cases, impaired renal function. In such patients, a renal biopsy is performed in order to confirm the diagnosis and guide therapeutic decisions. Unfortunately, a significant number of patients may present several flares of glomerulonephritis during the course of the disease $^{23}$ and, most of the time, each relapse requires a repeat-renal biopsy, as a 'gold standard' diagnostic procedure.

The reason why renal biopsies are needed for the diagnosis of SLE nephritis is mainly related to the lack of specificity of current biological markers for active renal disease in the context of the disease. Thus, increased proteinuria is a hallmark of active lupus nephritis, but can also reflect glomerular damage, or pre-eclampsia. Haematuria and pyuria have a low specificity, while the presence of casts has a low sensitivity. Serum dsDNA antibody titres increase and serum C3 concentrations decrease in patients with active renal disease, but the specificity of these observations is too low to translate into therapeutic guidelines. ${ }^{45}$ 
We recently found that a soluble form of the interleukin-7 receptor (sIL7R) is produced in the lupus kidney. ${ }^{6}$ In vitro experiments indicated that sIL7R production is induced upon stimulation by pro-inflammatory cytokines, in particular tumour necrosis factor $\alpha(\mathrm{TNF} \alpha){ }^{7}$ In a cross-sectional study, including healthy controls and SLE patients, with and without nephritis, we demonstrated that high serum sIL7R values discriminate patients with nephritis from other patients and controls, and correlate with systemic lupus erythematosus disease activity index (SLEDAI) scores. In the present study, we wanted to validate the diagnostic value of serum sIL7R measurements for the detection of active SLE nephritis in a longitudinal cohort of SLE nephritis patients followed at a single centre. Our results indicate that elevated serum sIL7R concentrations are associated or predict the occurrence of a renal flare in SLE and are of great value to better select patients in which a renal biopsy is warranted.

\section{PATIENTS AND METHODS}

Patients and samples

In all, 105 patients with SLE nephritis were included in this study. All patients met the 1982 revised criteria for the classification of SLE. ${ }^{8}$ Demographic and renal characteristics of the patients are displayed in table 1 . From July 2012, serum and urine samples were harvested in all patients after each visit at our lupus clinic, and stored at $-80^{\circ}$. At the time of the present study, median number of samples/patient was 3 (range 1-7); median total follow-up after the first sample was 15 months (range 1-19); and median interval between visits was 5 months (range 2-14). The study was approved by the ethics committee of the Université catholique de Louvain, and informed consent was obtained from all patients.

\section{sIL7R measurements and indices of disease activity}

sIL7R serum concentrations were determined by sandwich ELISA in serum and urine samples, as previously described, ${ }^{7}$ using a goat polyclonal hIL7R antibody (Sigma-Aldrich) as coating antibody and a mouse monoclonal hIL7R antibody as detecting antibody (Sigma-Aldrich). The sensitivity of the ELISA is $20 \mathrm{pmol} / \mathrm{mL}$. The presence of IL7 does not interfere with sIL7R detection. Normal range of serum sIL7R concentrations $(<505 \mathrm{pmol} / \mathrm{mL})$ was determined based on measurements made in a control population (mean+2 SDs), and published earlier. ${ }^{7}$ Similarly, serum sIL7R cut-off value for the detection of SLE nephritis activity was determined as the mean sIL7R concentration in non-nephritis SLE patients + 2 SDs $(<1042 \mathrm{pmol} / \mathrm{mL})$ using data collected in our previous study. ${ }^{6}$ Patients with a glomerular filtration $<60 \mathrm{~mL} / \mathrm{min} / 1.73 \mathrm{~m}^{2}$, yet inactive disease $(n=17)$, have significantly higher serum sIL7R values, compared with patients with a glomerular filtration $>60 \mathrm{~mL} / \mathrm{min} / 1.73 \mathrm{~m}^{2}$ in the same situation (see online supplementary figure 1 ). Patients with abnormal
Table 1 Demographic and renal characteristics of the patients at inclusion

\begin{tabular}{ll} 
F/M & $99 / 6$ \\
Mean age ( \pm SEM) & $37.4 \pm 10.7$ \\
N patients with no previous renal & 6 \\
BILAG A & \\
N patient with one previous renal & 69 \\
BILAG A & \\
N patients with two previous renal & 25 \\
BILAG A & \\
N patients with three or more & 5 \\
previous renal BILAG A & \\
Renal histology during the previous & \\
flares & \\
Class II & 4 \\
Class III & 22 (2 of whom also \\
& had class V) \\
Class IV & 77 (4 of whom also \\
& had class V) \\
IV (G) & 26 \\
IV (S) & 22 \\
IV (not determined) & 29 \\
Class V & 9 \\
No biopsy & 16 \\
Patients with GFR<60 mL/min & 17 \\
\hline BILAG, British Isles Lupus Assessment Group index.
\end{tabular}

kidney function were therefore discarded from the subsequent analyses. Urinary sIL7R values were normalised using creatine concentrations in the same samples.

Anti-dsDNA antibody (Ab) titres (Farr assay), urinary protein to creatine (UPC, expressed in $\mathrm{mg} / \mathrm{mg}$ ) ratios in spot urine specimens, serum C3 concentrations, glomerular filtration rates and clinical data were retrieved from the patients' records at the same time as sIL7R measurements. All clinical and laboratory data were generated at the same site.

Active renal disease was defined as the presence of a renal British Isles Lupus Assessment Group index (BILAG) A, according to the BILAG 2004 index definition, namely, two of more of the following criteria have to be present, provided (1), (4) or (5) is included: (1) deteriorating proteinuria (severe) defined as (a) urine dipstick increased by $\geq 2$ levels; (b) $24 \mathrm{~h}$ urine protein rising from $<0.20 \mathrm{~g}$ to $>1 \mathrm{~g}$; (c) $24 \mathrm{~h}$ urine protein rising from $>1 \mathrm{~g}$ by $\geq 100 \%$; (d) newly documented $24 \mathrm{~h}$ urine protein of $>1 \mathrm{~g}$; (e) UPC ratio rising from $<20 \mathrm{mg} / \mathrm{mmol}$ to $>100 \mathrm{mg} / \mathrm{mmol}$; (f) UPC ratio rising from $>100 \mathrm{mg} /$ mmol by $\geq 100 \%$; (g) newly documented UPC ratio of $>100 \mathrm{mg} / \mathrm{mmol}$; (h) urine albumin to creatine ratio rising from $<20 \mathrm{mg} / \mathrm{mmol}$ to $>100 \mathrm{mg} / \mathrm{mmol}$; (i) urine albumin creatine ratio rising from $>100 \mathrm{mg} / \mathrm{mmol}$ by $\geq 100 \%$; or (j) newly documented urine albumin to creatine ratio of $>100 \mathrm{mg} / \mathrm{mmol}$; (2) accelerated hypertension; (3) deteriorating renal function (severe) defined as (a) plasma creatine $>130 \mu \mathrm{mol} / \mathrm{l}$ and having risen to $>130 \%$ of previous value; (b) glomerular filtration rate (GFR) having fallen to $<67 \%$ of previous value; or (c) 
Figure 1 Biological indices of disease activity in a longitudinal cohort of SLE nephritis patients according to serum soluble form of the interleukin-7 receptor (sIL7R) concentrations.

Anti-double-stranded DNA antibodies $(A)$, urinary protein to creatine (UPC) ratio $(B)$ and serum $\mathrm{C} 3(\mathrm{C})$ are plotted in patients with serum SIL7R concentrations above (sIL7R high, $\mathrm{n}=25$ ) or below the renal cut-off (sIL7R low, $n=63$ ). $p$ Values by Mann-Whitney $U$ tests in (A) and (B), by Student's t test in (C).
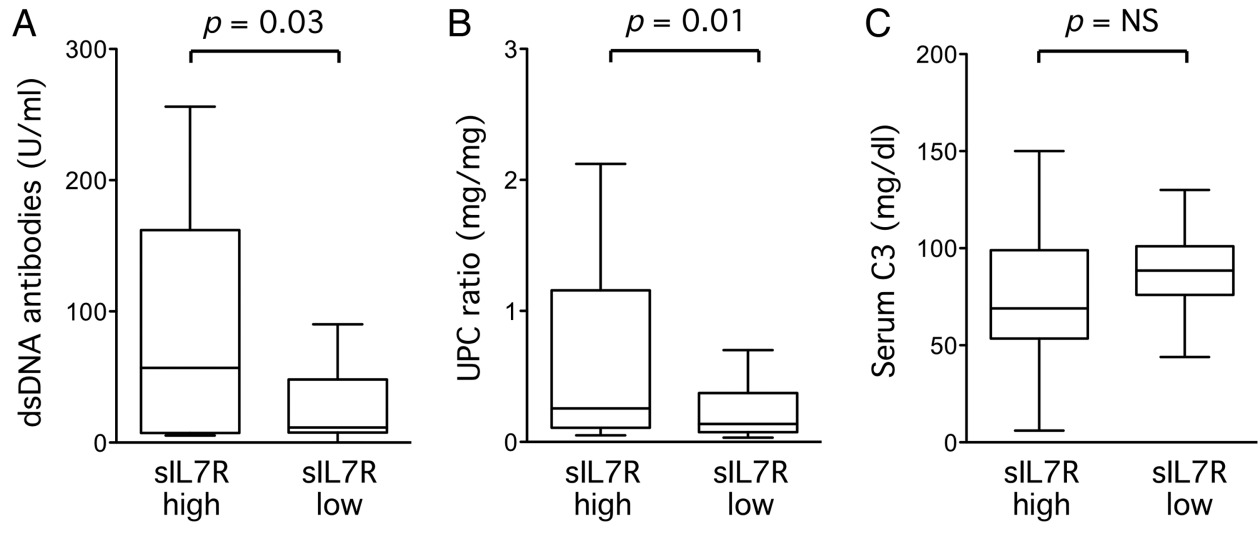

GFR $<50 \mathrm{~mL} / \mathrm{min}$, and last time was $>50 \mathrm{~mL} / \mathrm{min}$ or was not measured; (4) active urinary sediment; (5) histological evidence of active nephritis within last 3 months; and (6) nephrotic syndrome. ${ }^{9}$

\section{Statistical analyses}

Data are expressed as mean ( \pm SEM, unless stated differently) or median (range) and were analysed using Graphpad Prism V.4.00 software. Student's t test was used to compare variables with a normal distribution, and non-parametric tests (Mann-Whitney $U$ or Wilcoxon matched-pairs signed rank tests) for variables not distributed normally. For regression analyses, Spearman's correlation coefficients were calculated. A p value $<0.05$ was considered statistically significant. Receiving operator characteristic (ROC) curves were built in order to demonstrate the variations in sensitivity and specificity of increasing cut-off values for serum sIL7R and C3 concentrations, serum anti-dsDNA antibody titres and UPC ratio, used for the detection of a renal BILAG A. ROC curves were also built in order to demonstrate the effect of the combination of sIL7R with any of the three other tests for the detection of a renal BILAG A. In this case, a test was considered positive if the result of the test is above (or below in the case of serum C3) the increasing cut-off values, and if serum sIL7R is above $1042 \mathrm{pmol} / \mathrm{mL}$ (ie, the 'renal' sIL7R cut-off value).

\section{RESULTS}

Out of 88 SLE nephritis patients with a normal kidney function, 25 had serum sIL7R measurements above the renal cut-off value during longitudinal follow-up. In these patients, mean \pm SEM sIL7R concentration was 1678 \pm 160 versus $508 \pm 40 \mathrm{pmol} / \mathrm{mL}$ in the other patients. Patients with sIL7R serum concentrations above the renal cut-off had significantly higher dsDNA antibody titres and UPC ratios at that time point compared with the other patients (figure 1A and B). Serum C3 concentrations were lower in patients with serum sIL7R values above the renal cut-off, but the difference did not reach statistical significance (figure 1C).

Serum sIL7R values correlated with SLEDAI scores (Pearson $\mathrm{r}=0.48, \mathrm{p}<0.0001)$. Strikingly, 12 out of the 25 patients with serum sIL7R levels above the renal cut-off developed a renal BILAG A (seven International Society of Nephrology/Renal Pathology Society class IV(G), two class IV(S) and three class III kidney biopsies) at the time of or within the next 3 months following the abnormal measurement, while this was only the case in four (one class IV $(G)$, two class IV $(\mathrm{S})$, one had no biopsy) out of the 63 other patients $(\mathrm{p}<0.0001$ by Fisher's exact test) (figure 2).

Out of the patients with a serum sIL7R value above the renal cut-off, four also had a general, two had a mucocutaneous and one had a neurological BILAG A, in addition to the renal BILAG A (table 2). In patients with serum sIL7R below the renal cut-off, five had a musculo-skeletal, one had a general and one had a mucocutaneous BILAG A during the course of the study. There was no association between sIL7R serum levels and any of these manifestations (data not shown). ROC curves showing the evolution of sIL7R sensitivity and specificity at different cut-off values for the detection of a renal BILAG $\mathrm{A}$ are depicted in figure 3. As shown in the same figure, the detection of serum sIL7R concentrations above the renal cut-off improved the specificity of serum dsDNA antibody titres, serum C3 concentrations or UPC ratios for the detection of a renal BILAG A. The diagnostic metrics of the tests are recapitulated in table 3 .

In patients with serum sIL7R concentrations above the renal cut-off, administration of immunosuppressive therapy resulted in a significant decrease in serum sIL7R concentrations, while this was not the case in patients with serum sIL7R concentrations higher than the renal cut-off, not receiving any additional treatment (figure 4).

Finally, low urinary sIL7R concentrations were found in a majority of patients. There was no correlation between serum sIL7R and normalised urinary sIL7R 

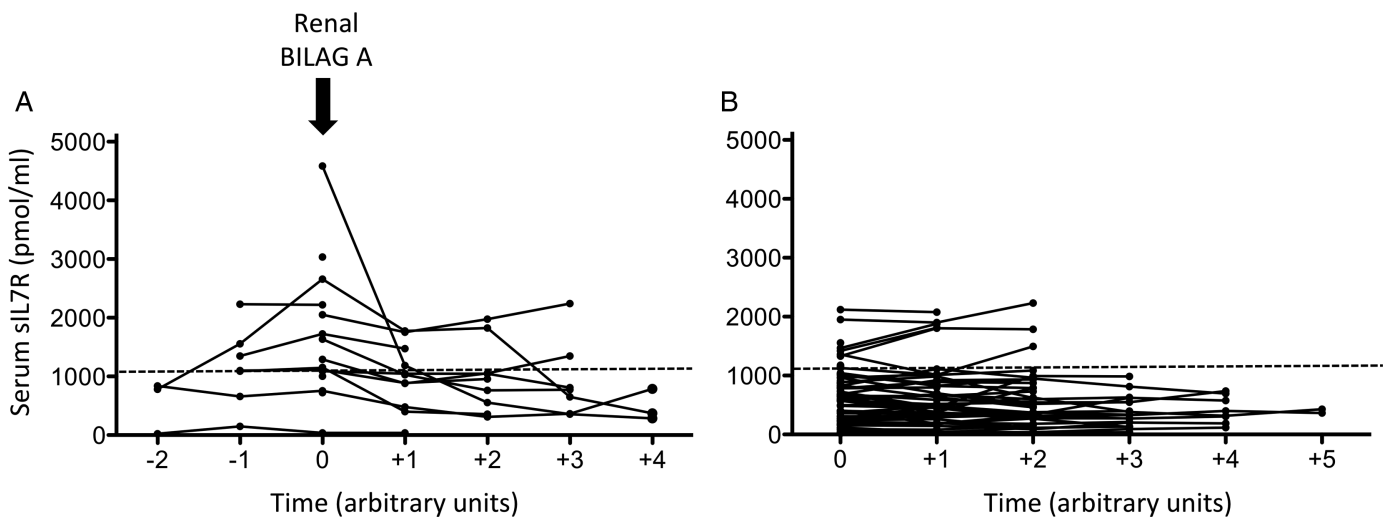

Figure 2 Serum soluble form of the interleukin-7 receptor (sIL7R) longitudinal measurements in 88 patients with SLE nephritis. sIL7R serum concentrations are depicted in patients who will $(A)(n=16)$ versus will not $(B)(n=72)$ present a renal BILAG $A$ during the time of the study. The time interval between two measurements is represented as an arbitrary unit, and varies between 2 and 14 (median 5) months. The dashed line represents the renal cut-off value for sIL7R serum concentrations (1042 pmol/mL).

concentrations measured at the same time points. Patients with a renal BILAG A did not display higher urinary sIL7R values compared with the other patients. There was a modest, albeit significant, correlation between normalised sIL7R concentrations and UPC ratios (Pearson $\mathrm{r}=0.27, \mathrm{p}<0.0001$ ).

\section{DISCUSSION}

In a previous study, we performed cross-sectional sIL7R measurements in sera of patients with and without active lupus nephritis, and found that elevated sIL7R values have a high sensitivity and specificity for kidney involvement in SLE. ${ }^{6}$ In the present study, we wanted to

Table 2 Clinical and biological characteristics of 25 (out of 88) SLE nephritis patients with serum sIL7R concentrations above the renal cut-off

\begin{tabular}{|c|c|c|c|c|c|c|}
\hline Age & Gender & $\begin{array}{l}\text { sIL7R } \\
\text { (pmol/mL) }\end{array}$ & $\begin{array}{l}\text { dsDNA Ab } \\
\text { titres (U/mL) }\end{array}$ & $\begin{array}{l}\text { Serum C3 } \\
\text { (mg/dL) }\end{array}$ & UPC ratio & Disease status \\
\hline 26 & $\mathrm{~F}$ & 4587 & 167 & 50 & 2.0 & Renal BILAG A \\
\hline 26 & M & 3035 & 32.5 & 68 & 1.3 & Renal and mucocutaneous BILAG A \\
\hline 46 & $\mathrm{~F}$ & 2658 & 289 & 46 & 5.4 & Renal BILAG A, 1 month later \\
\hline 44 & $\mathrm{~F}$ & 2241 & 125 & 60 & 0.9 & Renal and neurological BILAG A, 2 months later \\
\hline 49 & $\mathrm{~F}$ & 2232 & 43.8 & 89 & 0.2 & Renal BILAG D \\
\hline 47 & $\mathrm{~F}$ & 2220 & 110.7 & 81 & 0.13 & Renal BILAG A, 3 months later \\
\hline 56 & M & 2119 & 24.8 & 150 & 0.2 & Renal BILAG C \\
\hline 27 & $\mathrm{~F}$ & 1810 & 7.5 & 90 & 0.3 & Renal BILAG C \\
\hline 29 & $\mathrm{~F}$ & 1803 & 67 & 65.8 & 0.1 & Renal BILAG D \\
\hline 27 & $\mathrm{~F}$ & 1647 & 158.5 & 47 & 0.8 & Renal BILAG B \\
\hline 41 & $\mathrm{~F}$ & 1636 & 1520 & 57 & 2.1 & Renal, mucocutaneous and general BILAG A \\
\hline 43 & $\mathrm{~F}$ & 1557 & 5.3 & 97 & 0.2 & Renal BILAG D \\
\hline 51 & $\mathrm{~F}$ & 1495 & 38.7 & 134 & 0.6 & Renal BILAG D \\
\hline 47 & $\mathrm{~F}$ & 1466 & 5.9 & 101 & 0.2 & Renal BILAG D \\
\hline 28 & $\mathrm{~F}$ & 1348 & 255 & 69 & 2.1 & Renal and general BILAG A, 1 month later \\
\hline 33 & $\mathrm{~F}$ & 1291 & 161 & 53 & 1.9 & Renal BILAG A \\
\hline 24 & $\mathrm{~F}$ & 1175 & 7 & 124 & 0.1 & Renal BILAG B \\
\hline 19 & $\mathrm{~F}$ & 1155 & 179 & 62 & 0.17 & Renal and general BILAG A \\
\hline 62 & $\mathrm{~F}$ & 1156 & 6.3 & 96 & 0.05 & Renal BILAG D \\
\hline 50 & $\mathrm{~F}$ & 1154 & 7 & 61 & 0.1 & Renal BILAG C \\
\hline 28 & $\mathrm{~F}$ & 1148 & 2092 & 74 & 2.8 & Renal and general BILAG A, 2 months later \\
\hline 31 & $\mathrm{~F}$ & 1128 & 16.3 & 52 & 0.1 & Renal BILAG C \\
\hline 61 & $\mathrm{~F}$ & 1110 & 57 & 6 & 0.1 & Renal BILAG D \\
\hline 47 & $\mathrm{~F}$ & 1109 & 67.4 & 106 & 0.5 & Renal BILAG A, 3 months later \\
\hline 25 & $\mathrm{~F}$ & 1088 & 6.2 & 114 & 5.6 & Renal and general BILAG A \\
\hline
\end{tabular}


Figure 3 Receiving operator characteristic (ROC) curves displaying the performances of serum soluble form of the interleukin-7 receptor (sIL7R) (A), serum anti-double-stranded DNA antibodies (B), serum C3 (C) and urinary protein to creatine (UPC)

(D) measurements for the detection of a renal BILAG $A$ in a cohort of SLE nephritis patients. The left panels show the variations in sensitivity and specificity of the indicated test according to several cut-off values. The dot surrounded by a circle corresponds to the cut-off values generally used for these tests (serum sIL7R=1042 pmol/ $\mathrm{mL}$; anti-double-stranded DNA antibodies $=50 \mathrm{U} / \mathrm{mL}$; serum $\mathrm{C} 3=85 \mathrm{mg} / \mathrm{dL}$; UPC ratio=0.5).

The right panels show the ROC curves of the same tests (several cut-off values), when associated with the necessity of having a serum sIL7R value above the renal cut-off, for the detection of a renal BILAG A.
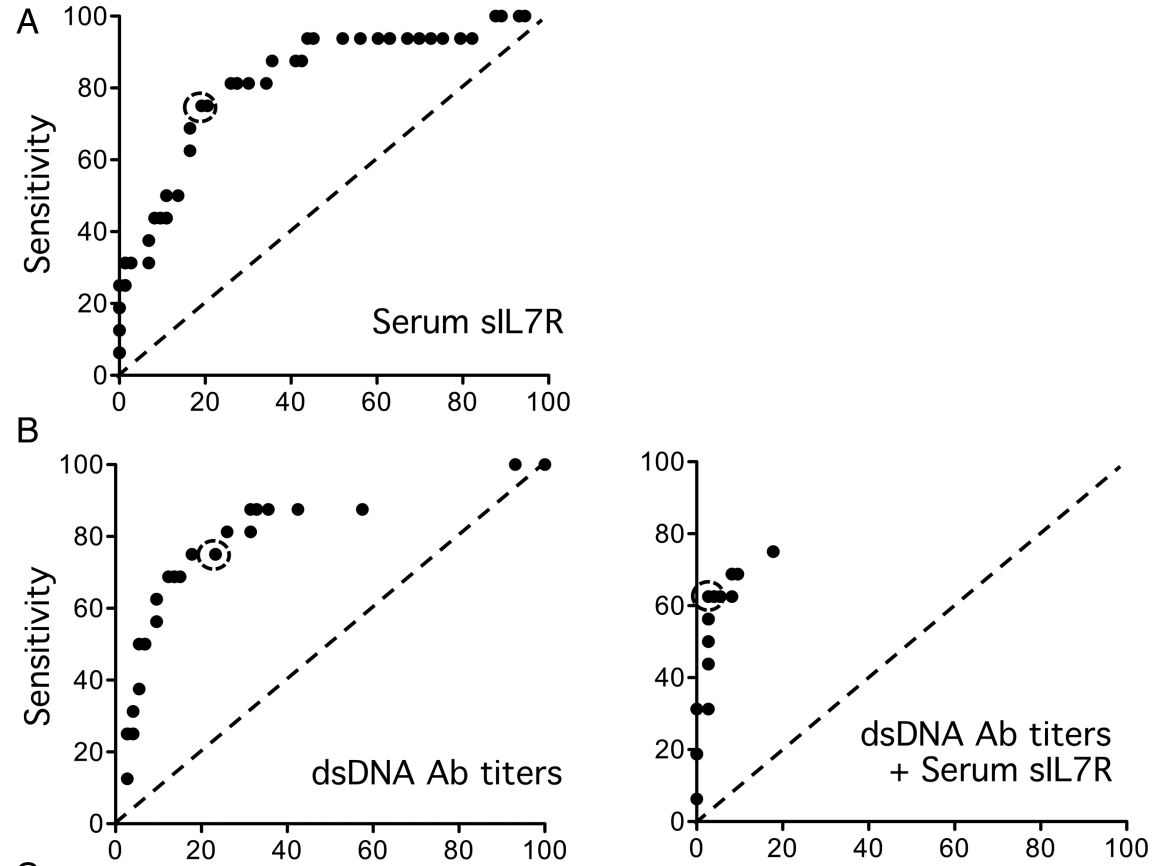

$$
\text { C }
$$
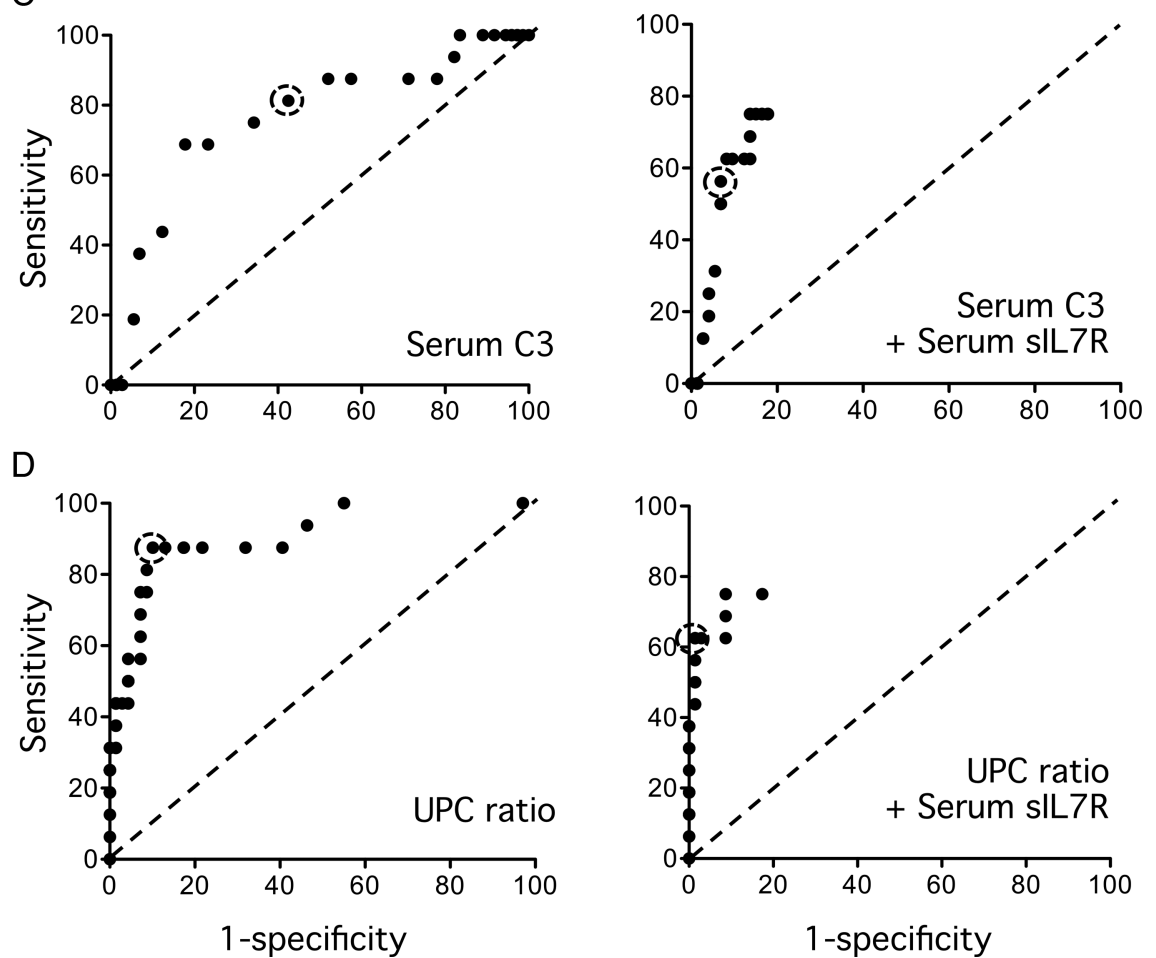

confirm the association between serum sIL7R and kidney involvement in SLE in a prospective cohort of patients followed at a single centre. Our results confirm a strong association between serum sIL7R and renal disease activity in lupus patients. When the occurrence of a renal BILAG $\mathrm{A}$ is used to define active renal disease in SLE, serum sIL7R concentrations have an elevated negative predictive value $(93.6 \%)$ and a $48.0 \%$ positive predictive value for the detection of active renal disease.

Our interest in serum sIL7R measurements originates from our observations in synovial tissue and serum samples from patients with rheumatoid arthritis
(RA). ${ }^{10}{ }^{11}$ We found that IL7R mRNA is induced in synovial fibroblasts upon stimulation with pro-inflammatory cytokines, such as TNF $\alpha$, IL1 $\beta$ or IL17. We demonstrated that fibroblasts have the ability to generate a splice variant of the IL7R mRNA, which lacks the transmembrane domain of the receptor, thereby resulting in the production of a secreted form of the molecule. In RA patients, sIL7R serum concentrations are higher than in controls, and very high values are associated with poor response to (methotrexate and TNF-blocking) therapy, probably because they reflect very active inflammatory processes in the synovium. ${ }^{7}$ 

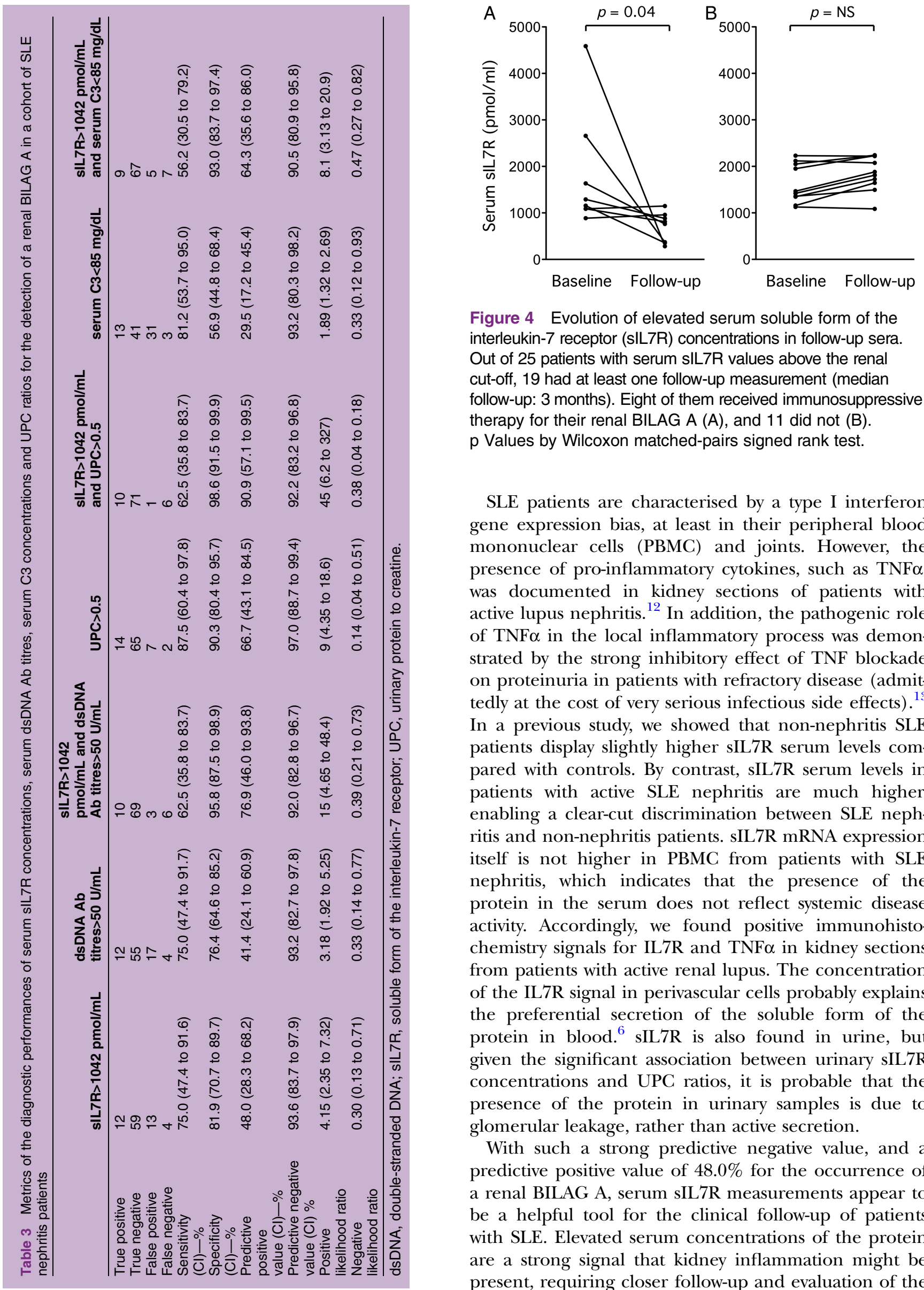

Figure 4 Evolution of elevated serum soluble form of the interleukin-7 receptor (sIL7R) concentrations in follow-up sera. Out of 25 patients with serum sIL7R values above the renal cut-off, 19 had at least one follow-up measurement (median follow-up: 3 months). Eight of them received immunosuppressive therapy for their renal BILAG $A(A)$, and 11 did not $(B)$. $p$ Values by Wilcoxon matched-pairs signed rank test.

SLE patients are characterised by a type I interferon gene expression bias, at least in their peripheral blood mononuclear cells (PBMC) and joints. However, the presence of pro-inflammatory cytokines, such as TNF $\alpha$, was documented in kidney sections of patients with active lupus nephritis. ${ }^{12}$ In addition, the pathogenic role of TNF $\alpha$ in the local inflammatory process was demonstrated by the strong inhibitory effect of TNF blockade on proteinuria in patients with refractory disease (admittedly at the cost of very serious infectious side effects). ${ }^{13}$ In a previous study, we showed that non-nephritis SLE patients display slightly higher sIL7R serum levels compared with controls. By contrast, sIL7R serum levels in patients with active SLE nephritis are much higher, enabling a clear-cut discrimination between SLE nephritis and non-nephritis patients. sIL7R mRNA expression itself is not higher in PBMC from patients with SLE nephritis, which indicates that the presence of the protein in the serum does not reflect systemic disease activity. Accordingly, we found positive immunohistochemistry signals for IL7R and TNF $\alpha$ in kidney sections from patients with active renal lupus. The concentration of the IL7R signal in perivascular cells probably explains the preferential secretion of the soluble form of the protein in blood. ${ }^{6}$ sIL7R is also found in urine, but given the significant association between urinary sIL7R concentrations and UPC ratios, it is probable that the presence of the protein in urinary samples is due to glomerular leakage, rather than active secretion.

With such a strong predictive negative value, and a predictive positive value of $48.0 \%$ for the occurrence of a renal BILAG A, serum sIL7R measurements appear to be a helpful tool for the clinical follow-up of patients with SLE. Elevated serum concentrations of the protein are a strong signal that kidney inflammation might be present, requiring closer follow-up and evaluation of the 
need for a kidney biopsy. Of note, $52 \%$ of patients with serum sIL7R concentrations above the renal cut-off do not develop a renal BILAG A. In many of them, low grade proteinuria (UPC between 0.2 and 1), elevated dsDNA antibody titres or decreased serum C3 is compatible with grumbling disease, and long-term follow-up of these patients will be of interest to assess increased disease activity or modifications in renal function in the future. Long-term follow-up will also indicate whether the few patients (three out of 25) with elevated serum sIL7R, yet low dsDNA antibody titres, normal C3 and $\mathrm{UPC}<0.2$, are genuine false positives.

In this perspective, it should be stressed that our definition of a renal flare, based on the observation of a renal BILAG A, is potentially restrictive, and could result by itself in an underestimation of the specificity of serum sIL7R as a marker of renal disease activity in SLE. There are several clinical definitions of a renal flare available in SLE, which result in different categorisations of the patients, but there is no gold standard. We believe that a renal BILAG A score truly reflects renal disease activity in our series, since 15 out of the 16 patients falling under that category received new or additional immunosuppressive therapy at that time; one patient did not receive additional treatment because the renal flare was due to lack of compliance to therapy.

Several candidate biomarkers are presently under scrutiny as markers of disease activity in SLE nephritis. The most promising candidates are measured in urine samples; thus, urinary TNF-like inducer of apoptosis (TWEAK), ${ }^{14}$ monocyte chemoattractant protein- $1^{15}$ or neutrophil gelatinase-associated lipocalin ${ }^{15}{ }^{16}$ concentrations were shown in several studies to associate with clinical or histological markers of disease activity, or even predict the occurrence of a flare of the disease. The absence of significant correlations between urinary concentrations of these markers and proteinuria suggest that their presence in the urine is due to an active secretion process rather than glomerular leakage. Several serum markers were suggested to be associated with disease activity in the lupus kidney, but the described associations were either not consistent or not validated in independent studies.

In our series, UPC ratio is a very good marker for the detection of active renal disease, but there is some circularity here, since either newly documented or rising proteinuria is part of the definition of a renal BILAG A score. Systemic markers of disease activity (anti-dsDNA antibodies, serum C3) also show very good performances for the detection of renal flares, which is not surprising in this cohort of patients who were selected for the presence of renal disease. However, it is known that these markers are not specific to kidney involvement in SLE, by contrast to serum sIL7R. ${ }^{6}$ In addition, despite the very favourable context in which the performance of these systemic markers of disease activity is evaluated, combination of any of them with the presence of elevated serum sIL7R concentration still increases their specificity for the detection of a renal BILAG A. This can be very useful in doubtful situations (eg, a pregnant woman with high dsDNA antibody titres, low serum C3, increased UPC ratio, yet low serum sIL7R concentrations has a very low probability of developing a renal BILAG A flare, according to our results). In the future, it is probable that such combination of two or more markers in decision matrices will be routinely used in the clinical care of patients with complex disease manifestations.

In conclusion, our results indicate that serum sIL7R is a good marker of disease activity in SLE nephritis, as it is produced locally upon stimulation by pro-inflammatory cytokines. Elevated serum sIL7R concentrations (in SLE patients with a normal kidney function) increase the probability of a (pending) renal flare. By contrast, sIL7R concentrations below the renal cut-off are associated with a very low probability of active renal disease.

Contributors BL, VB and FH designed the study; BL, SNH, ALM collected the experimental data, $\mathrm{BL}, \mathrm{VB}$ and $\mathrm{FH}$ interpreted the data, $\mathrm{BL}$ and $\mathrm{FH}$ wrote the manuscript.

Funding This work was supported by grants from the Fonds de la Recherche Scientifique et Médicale (FRSM-Communauté française de Belgique) and Cap48 (charity supported by the Radio Télévision belge francophone).

Competing interests None.

Patient consent Obtained.

Ethics approval Comité d'éthique biomédicale hospitalo-facultaire de l'Université catholique de Louvain.

Provenance and peer review Not commissioned; externally peer reviewed.

Data sharing statement All the laboratory data are available on request to the corresponding author.

Open Access This is an Open Access article distributed in accordance with the Creative Commons Attribution Non Commercial (CC BY-NC 4.0) license, which permits others to distribute, remix, adapt, build upon this work noncommercially, and license their derivative works on different terms, provided the original work is properly cited and the use is non-commercial. See: http:// creativecommons.org/licenses/by-nc/4.0/

\section{REFERENCES}

1. Hahn BH. Antibodies to DNA. N Engl J Med 1998;338:1359-68.

2. Houssiau FA. Toward better treatment for lupus nephritis. $N$ Engl $J$ Med 2011;365:1929-30.

3. Houssiau FA, Lauwerys BR. Current management of lupus nephritis. Best Pract Res Clin Rheumatol 2013;27:319-28.

4. Ter Borg EJ, Horst G, Hummel EJ, et al. Measurement of increases in anti-double-stranded DNA antibody levels as a predictor of disease exacerbation in systemic lupus erythematosus. A long-term, prospective study. Arthritis Rheum 1990;33:634-43.

5. Bootsma $H$, Spronk $P$, Derksen $R$, et al. Prevention of relapses in systemic lupus erythematosus. Lancet 1995;345:1595-9.

6. Badot V, Luijten RK, van Roon JA, et al. Serum soluble interleukin-7 receptor is strongly associated with lupus nephritis in patients with systemic lupus erythematosus. Ann Rheum Dis 2013;72:453-6.

7. Badot V, Durez P, Van den Eynde BJ, et al. Rheumatoid arthritis synovial fibroblasts produce a soluble form of the interleukin-7 receptor in response to pro-inflammatory cytokines. J Cell Mol Med 2011;15:2335-42

8. Tan EM, Cohen AS, Fries JF, et al. The 1982 revised criteria for the classification of systemic lupus erythematosus. Arthritis Rheum 1982;25:1271-7.

9. Isenberg DA, Rahman A, Allen E, et al. BILAG 2004. Development and initial validation of an updated version of the British Isles Lupus Assessment Group's disease activity index for patients with systemic lupus erythematosus. Rheumatology (Oxford) 2005;44:902-6.

10. Nzeusseu Toukap A, Galant C, Theate I, et al. Identification of distinct gene expression profiles in the synovium of patients with systemic lupus erythematosus. Arthritis Rheum 2007;56:1579-88. 
11. Badot V, Galant C, Nzeusseu Toukap A, et al. Gene expression profiling in the synovium identifies a predictive signature of absence of response to adalimumab therapy in rheumatoid arthritis. Arthritis Res Ther 2009;11:R57.

12. Malide D, Russo P, Bendayan M. Presence of tumor necrosis factor alpha and interleukin-6 in renal mesangial cells of lupus nephritis patients. Hum Pathol 1995;26:558-64.

13. Aringer M, Houssiau F, Gordon C, et al. Adverse events and efficacy of TNF-alpha blockade with infliximab in patients with systemic lupus erythematosus: long-term follow-up of 13 patients. Rheumatology (Oxford) 2009;48:1451-4.
14. Schwartz N, Rubinstein T, Burkly LC, et al. Urinary TWEAK as a biomarker of lupus nephritis: a multicenter cohort study. Arthritis Res Ther 2009;11:R143.

15. Brunner HI, Bennett MR, Mina R, et al. Association of noninvasively measured renal protein biomarkers with histologic features of lupus nephritis. Arthritis Rheum 2012;64: 2687-97.

16. Brunner $\mathrm{HI}$, Mueller M, Rutherford $\mathrm{C}$, et al. Urinary neutrophil gelatinase-associated lipocalin as a biomarker of nephritis in childhood-onset systemic lupus erythematosus. Arthritis Rheum 2006;54:2577-84. 